\title{
Study of the adherence capacity of microbial biofilms on titanium versus zirconium dioxide (Zirconia) surfaces
}

\author{
Teodora MARCU ${ }^{1}$, Augustin MIHAI ${ }^{2}$, Mihai BURLIBASA², Marcela POPA ${ }^{3}$, \\ Corina Marilena CRISTACHE², Viorel PERIEANU ${ }^{2}$, Mihaela CHIRILA², Madalina PERIEANU², \\ Madalina MALITA2 ${ }^{2}$, Radu COSTEA², Raluca COSTEA ${ }^{4}$, Iuliana BABIUC², Gabriela TANASE², \\ Irina Adriana BEURAN² ${ }^{2}$, Constantin Florin DRAGAN², Liliana BURLIBASA ${ }^{3}$ \\ 1 "Dunarea de Jos" University, Galati, Romania \\ 2 "Carol Davila" University of Medicine and Pharmacy, Bucharest, Romania \\ ${ }^{3}$ Faculty of Biology, University of Bucharest, Romania \\ ${ }^{4}$ Private practice, Brasov, Romania
}

\begin{abstract}
Introduction. An important role in the appearance of acute or chronic infections is played by bacterial biofilms that contain several bacterial species and that develop preferentially on inert surfaces, dead tissues and medical devices.

Purpose. In this material we tried to make an interesting study, regarding the adhesion capacity of microbial biofilms characteristic of the oral cavity of human subjects on the surface of materials used for industrial scale manufacturing of dental implants: titanium and zirconium dioxide (Zirconia).

Material and methods. For this study were used plates of Ti4 and zirconia, on which adhesion of different bacterial strains belonging to the species Enterobacter cloacae, Klebsiella oxytoca and Klebsiella pneumonia were tested.

Results and discussions. A rather high microbial load was observed on both types of materials for all types of bacterial strains studied. For certain types of strains, a lower colonization was noted in the case of zirconium dioxide compared to Ti4 surfaces.

Conclusions. Although Zirconia has been reported to have a lower susceptibility to bacterial adhesion, our study contradicts this aspect specified in the literature. Both titanium and zirconium dioxide are promptly colonized by existing bacteria on the teeth left in the oral cavity.
\end{abstract}

Keywords: microbial biofilm, titanium, zirconium dioxide, microbial adhesion

\section{INTRODUCTION}

Human being has been the victim of acute epidemic infectious diseases, caused in more than half of the cases of bacterial species, living together on / or in the human body or in the environment, causing chronic in- fections sometimes very serious, such as immuno-compromised patients (1-5).

An important role in the occurrence of acute or chronic infections is played by bacterial biofilms that contain several bacterial species and that grow preferentially on inert surfaces, dead tissues and often on 
medical devices, including prosthetic devices and other materials for medical use, for example: sutures (Staphylococcus epidermidis, S. aureus), contact lenses (Pseudomonas aeruginosa, Gram-negative shells), prosthetic restorations on implants or classic (fixed and mobile), occlusal rims, trial dentures, impression materials and dental impressions (various bacteria and fungi), venous catheters (Staphylococcus epidermidis), mechanical valves (Staphylococcus epidermidis, S. aureus), endotracheal tubes (different bacteria and fungi) etc. (6-8).

Examination by electron microscopy on the surface of medical devices or tissues taken from patients with chronic infections, unrelated with medical devices, revealed the presence of bacterial biofilms, which appear surrounded by a matrix of extracellular polysaccharides (1-5).

\section{PURPOSE}

Titanium has many applications in dentistry, being used in almost all areas of this medical specialty, but especially in implant-prosthetic rehabilitation. In implant-prosthetic rehabilitation, titanium can be used either in the form of dental implants, or in the form of cast or processed (milled) using computerized CAD-CAM systems in the manufacture of metal infrastructure, in the case of fully physiognomic mixed metal-ceramic implant-supported prosthetic restorations.

Another material used successfully in these first decades of the $21^{\text {st }}$ century in implant-prosthetic rehabilitation is zirconium dioxide $\left(\mathrm{ZiO}_{2}\right)$ or more simply Zirconia, as it is known in the literature. In implant-prosthetic rehabilitation, this revolutionary material is used, similar to titanium, both for the manufacture of dental implants and for the manufacture of infrastructure for fully physiognomic prosthetic restorations with implant-supported ceramic component. Among the major advantages of using zirconium dioxide (Zirconia) are the following aspects: very good biocompatibility, excellent physiognomic appearance, very good resistance to pressure and abrasion etc. (1-5,9).

But what should be mentioned in this study is that both materials, titanium and zirconium dioxide (Zirconia) being the only materials actually used in the manufacture of dental implants, both types of tissue integrations (bone and gingival) that occur (gingival integration in human subjects and epithelial-conjunctive integration in experimental studies in animals, but also bone integration in human subjects, as well as in animal studies) are very good. However, in order to achieve a proper tissue integration, a number of conditions need to be met, of which the degree of adhesion to these 2 materials of microbial biofilms must be specified in particular. Basically, depending on the biofilms formed on the surface of dental implants made of tita- nium or zirconium dioxide (Zirconia), their degree of infectivity, etc., the tissue integration (epithelial, conjunctival and bone) of these medical devices can be decisively influenced, in the context of an implant-prosthetic rehabilitation of a greater or lesser extent (10-13).

Thus, we tried to make a very interesting study, even if it is only a preliminary one, regarding the ability of some microbial biofilms characteristic of the oral cavity of human subjects, on the surface of some materials used for industrial scale manufacturing of dental implants: titanium and zirconium dioxide (Zirconia).

Specifically, the objectives of this study are to obtain methodological and scientific information on bacterial biofilms, relevant to human health, in order to improve the prophylactic and therapeutic methods of infections caused by them, to assess the opportunity and effectiveness of antimicrobial therapy, by studying the resistance of biofilms to the action of antimicrobial substances.

\section{MATERIALS AND METHODS}

The study was performed on bacterial strains from the collection of the Research Institute of the University of Bucharest, Department of Life Environment and Earth Sciences. The strains tested are part of the Enterobacteriaceae family and belong to the species Enterobacter cloacae, Klebsiella pneumoniae and Klebsiella oxytoca. These microbial strains have been isolated from a number of 36 patients (we are talking about volunteer subjects who have given their consent for this harvesting maneuver), implant-prosthetic rehabilitated patients in the last 3 years (fixed implant-supported prosthetic restorations) and were identified by MALDI-TOF mass spectroscopy, Bruker.

The tested bacterial strains were harvested using dental scaling instruments from the dental plaque localized below or above gum line, from the aforementioned volunteer patients. After sampling, the samples were kept and transported sterile in RTM (Reduced Transport Medium; - container specially equipped with transport medium) to the Research Institute of the University of Bucharest, Department of Life, Environment and Earth Sciences, where they were processed, entering in the collection of microbial strains of this research institution. Certainty identification of microbial strains was achieved by establishing the biochemical profile, with the help of API tests (Analytical Profile Index) (1416). Subsequently, microbial strains belonging to the family Enterobacteriaceae and belonging to the species Enterobacter cloacae (Enterobacter cloacae 1, Enterobacter cloacae 2, Enterobacter cloacae 17), Klebsiella pneumonia (Klebsiella pneumoniae17, Klebsiella pneumonia 173) and Klebsiella oxytoca (Klebsiella oxytoca 22 and Klebsiella oxytoca 223) were tested. 


\section{Evaluation of the microbial biofilms' formation on inert substrate}

The quantification of biofilm formation on surfaces represented by commercially pure titanium grade 4 (identified as (Ti4) (presented in the form of plates) and sintered zirconia tablets was determined by evaluating the number of colony-forming units (CFU). The materials used, after pre-sterilization with UV for 30 minutes on each side, were contacted with an inoculum of $1.5 \mathrm{x}$ $105 \mathrm{CFU} / \mathrm{mL}$ from each strain for 24 hours.

After incubation, each material was carefully washed to remove unadhered bacteria, deposited in $500 \mu \mathrm{l}$ saline and vortexed for 30 seconds at maximum speed to remove adherent bacteria on the surface. From the resulting solution, serial decimal dilutions were made and seeded in agar medium to determine the number of $\mathrm{CFU} / \mathrm{mL}$.

\section{RESULTS AND DISCUSSIONS}

The oral microbiome comprises about 700 phylotypes, of which more than half can be present at any time in the oral cavity of a healthy individual (17).

The initial adhesion of bacteria on the surfaces in the oral cavity occurs very quickly after cleaning (brushing) the teeth. Bacterial adhesion has been reported to occur within 5 minutes after inserting sterile enamel or synthetic carbonic hydroxyapatite surfaces into the oral cavity (18).

Implant-supported prosthetic restorations are a treatment widely used in dental practice. Numerous studies published in the literature report high success rates over time, but late clinical complications have also been reported, which, if not identified and treated in time, can lead to serious implantation failures. Complications are mainly due to peri-implant infections (periimplantitis), as a result of an inflammatory process caused by microbial penetration through the im- plant-abutment interface and colonization of implant surfaces/components (19).

In this study, the bacterial strains were put in contact with the test materials (commercially pure titanium grade $4-\mathrm{Ti} 4$ and Zirconia) in liquid medium (Figure 1). Their ability to adhere to the surfaces they came in contact with was quantified by determining the number of CFU/ml (Figure 2).

The analysis of the data obtained after determining the number of CFU / $\mathrm{mL}$ showed that the bacterial adhesion is similar in terms of the two materials tested, namely the fragments of Ti4 and Zirconia (sintered) (Figure 3).

Specifically, a rather high microbial load was observed on both types of materials for all types of bacterial strains studied, in the context in which in the literature, Zirconia (zirconium dioxide) has been reported as a revolutionary material not only in terms of biocompatibility, physiognomy and/or resistance to pressure and abrasion, but also a material with a strong antibacterial action, on which microbial biofilms adhere with considerable difficulty, but with a very low survival rate. Specifically, Zirconia has been reported to have a lower susceptibility to bacterial adhesion (20). However, the study conducted by us contradicts certain existing data in the literature.

As an example, in our study, in the case of Klebsiella sp. (see especially Klebsiella pneumonia strain 173) there is a slightly lower colonization on zirconium dioxide compared to commercially pure titanium grade 4 (Ti4). However, adhesion to a surface is conditioned by a number of factors, including chemical composition and surface topography.

Adherence is a major advantage for pathogenic bacteria, in terms of nutrient assurance, protection against antibodies and lysozyme, etc. Their multiplication, after adhesion, takes place at a much higher rate than non-adherent cells (21).
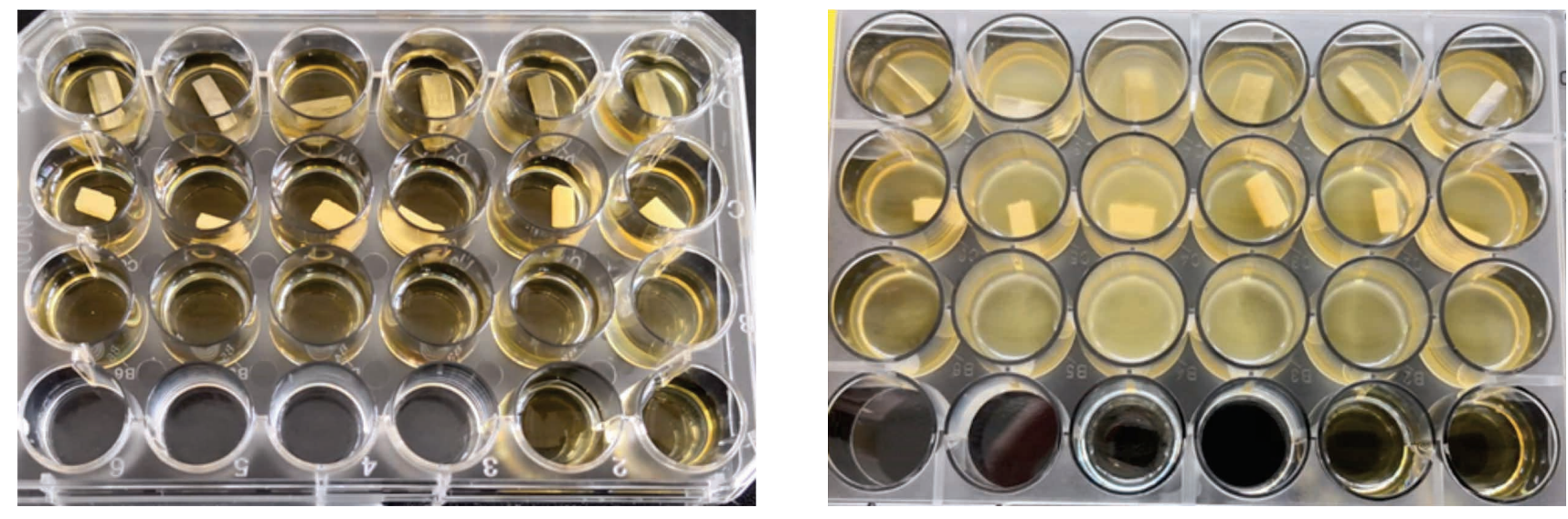

b

FIGURE 1. Appearance of Ti4 and Zirconia fragments (samples) in contact with bacterial strains (initial contact - a and appearance after 24 hours - $b$ ) 

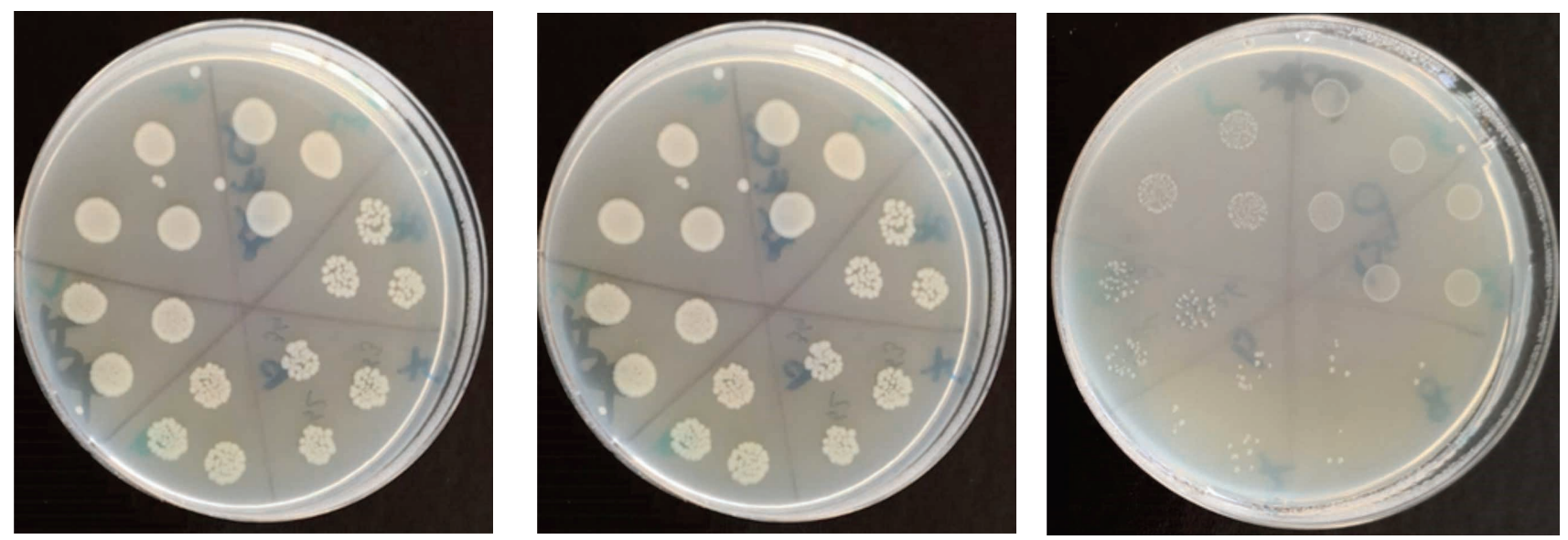

FIGURE 2. Quantification of the biofilm developed on the surface of the materials by sowing on an agar medium

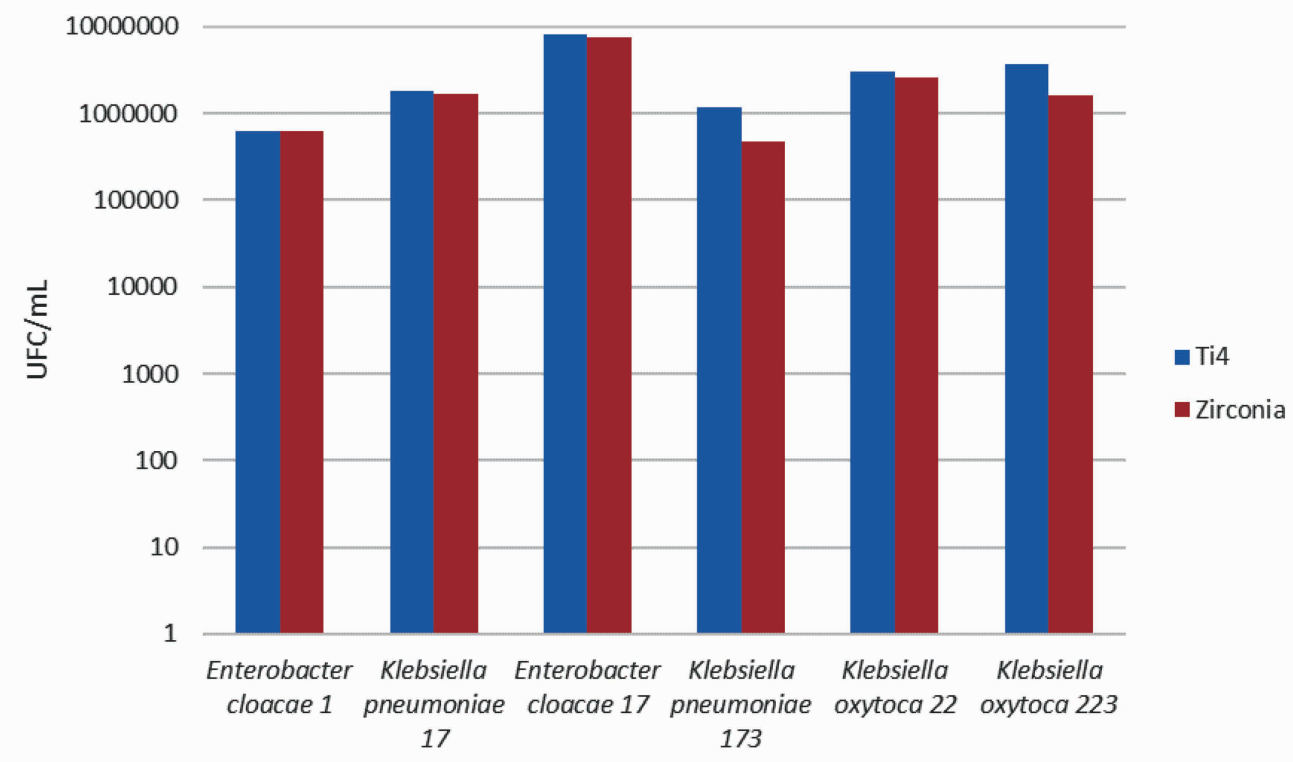

FIGURE 3. Quantification of the biofilm developed on the surfaces of commercially pure titanium grade 4 (Ti4) and zirconium dioxide (Zirconia)

Both titanium and zirconium dioxide are promptly colonized by a bacterial community closely related to the microbial model of the remaining teeth (19).

Studies in the literature have indicated that the surface roughness is a major factor, which influences the adhesion especially in titanium, and much less in zirconium dioxide (22). More specifically, Zirconia is recommended as the material of choice in implant-prosthetic rehabilitation both because of its biocompatibility and because it has a much lower susceptibility to microbial biofilms compared to other materials of major utility in oral implantology (20-22).

But the oral microbiota is a risk factor when it is associated with dental implants made of two components: the implant itself and the implant abutment. Geodes and cavities inherent in dental implant-implant abutment assemblies can act as highly retentive areas for microbial biofilms (they have been likened in the literature to true caps for microbial biofilms), housing bacterial species that can cause inflammatory reactions in soft tissues around dental implant, which in a relatively short time can evolve and lead to implant failure.

However, studies on microbial adhesion in various materials used in dental practice and the impact over time of complex oral microbial biofilm on the clinical parameters of implant-worn prosthetic restorations are not yet very conclusive (20).

\section{CONCLUSIONS}

On both types of materials, a rather high microbial load was observed for all bacterial strains studied.

In the case of Klebsiella sp. (see especially Klebsiella pneumonia 173 strain), a slightly lower colonization of zirconium dioxide compared to commercially pure titanium grade 4 (Ti4) is observed. 
Although Zirconia has been reported to have a lower susceptibility to bacterial adhesion, our study contradicts this aspect specified in the literature.

Both titanium and zirconium dioxide are promptly colonized by existing bacteria on the teeth left in the oral cavity.

Starting from this very ability to colonize of microbial strains, we tried to find plant extracts with antimicrobial properties that would decisively disorganize the adhesion of microbial biofilms, but at this time we managed only very accurate studies in terms of microbiology and biocompatibility (which we will present in other articles), and in the future we will study the effect of these herbal compounds on possible corrosion processes, especially on titanium and its alloys.

\section{Acknowledgement}

In this article, all the authors have equal contribution with the first author.

Conflict of interest: none declared Financial support: none declared

\section{REFERENCES}

1. Burlibașa M, Dumitru SG, Tănase G, Sfarghiu L. Flora cavității bucale - element de contaminare directă și indirectă în reabilitarea implanto-protetică. In: Trăistaru T, Burlibașa M, lonescu I. Progrese în medicina dentară, Vol. III, București: Ed. Ars Docendi, 2012:48-63.

2. Burlibașa M, lonescu I, Bodnar D, et al. Aspecte teoretice și practice ale formării, dezvoltării și combaterii biofilmelor microbiene în medicina dentară. Medicina Modernă. 2008;15(10):544-547.

3. Costerton JW, Lewandowski Z, Caldwell DE, et al. Microbial biofilms. Annu Rev Microbiol. 1995;49:711-745.

4. Costerton JW, Steward PS, Greenberg EP. Bacterial biofilms: a common cause of persistent infections. Science. 1999;284(5418):1318-1322.

5. Donlan RM, Costerton JW. Biofilms: Survival mechanism of clinically relevant microorganisms. Clin Microbiol Rev. 2002;15(2):167-193.

6. Burlibasa L, Chifiriuc MC, Lungu MV, et al. Synthesis, physico-chemical characterization, antimicrobial activity and toxicological features of $\mathrm{Ag}-\mathrm{ZnO}$ nanoparticles. Arab J Chem. 2020;13(2):4180-4197.

7. Totu EE, Cristache CM, Islidak I, et al. Preliminary studies on cytotoxicity and genotoxicity assessment of the PMMA-TiO2 nanocomposites for stereolithographic complete dentures manufacturing. Rev Chim. 2018; 69(5):1160-1165.

8. Cristache CC, Totu EE, Burlibasa M, et al. Preliminary study on genotoxicity assessment of an innovative topical treatment for periodontal disease. Rev Chim. 2020;71:145-150.

9. Cristache C, Burlibașa M, Cristache G, et al. Zirconia and its biomedical applications. Met Int. 2011;16(7):18-23.

10. Jamous $S$, Burlibașa L New insights in molecular analysis of gene regulation - an epigenetic overview. Lett Appl Nanobioscience. 2018;7(1-2):511-522.

11. Esian D, Man A, Burlibasa L et al. Salivary level of Streptococcus mutans and Lactobacillus spp. Related to a high risk of caries disease. Rom Biotechnol Lett. 2017;22(2):12496-12503.

12. Popescu SM, Popescu FD, Burlibaşa L. In vitro biocompatibility of zirconia. Met Int. 2010;15(4):14-26.

13. Mocuța D, Popovici IA, Burlibașa L et al. Impact of the living conditions on population health. Met Int. 2009;14:17-19.

14. BIOMÉRIEUX, API® STAPH Ref: 20500. Available at: https://biomerieuxdirect.com/ industry/Bacteriology/ID-AST-Manual/API/ ID-Manual/Api-galleries-Staphylococci/ API\%26reg-STAPH-\%2825STRIPS\%2B25M EDIA\%29/p/20500.

15. BIOMÉRIEUX, API® 20 STREP Ref: 20600. Available at: https://biomerieuxdirect.com/ industry/Bacteriology/ID-AST-Manual/
ID-AST-API/ID-Manual/Api-galleriesStreptococci/API\%26reg-20-STREP\%2825STRIPS\%2B25MEDIA\%29/p/20600.

16. BIOMÉRIEUX, API® 20A Ref: 20300. Available at: https://biomerieuxdirect.com/ industry/Bacteriology/ID-AST-Manual/ ID-AST-API/ID-Manual/Api-galleriesAnaerobes/API\%26reg-20A-\%2825STRIPS \%2B25MEDIA\%29/p/20300.

17. Palmer RJ Jr. Composition and development of oral bacterial communities. Periodontol 2000. 2014;64(1):20-39.

18. Jakubovics NS. Intermicrobial interactions as a driver for community composition and stratification of oral biofilms. $J \mathrm{Mol}$ Biol. 2015;427(23):3662-75.

19. De Freitas AR, de Oliveira Silva TS, Ribeiro $\mathrm{RF}$, et al. Oral bacterial colonization on dental implants restored with titanium or zirconia abutments: 6-month follow-up. Clin Oral Investi. 2018;22(6):2335-2343.

20. do Nascimento C, Sucena Pita M, de Souza Santos E et al. Microbiome of titanium and zirconia dental implants abutments. Dent Mat. 2016;32(1):93-101.

21. Chifiriuc CM, Mihăescu G, Lazăr V. Microbiologie și virologie medicală. București: Ed. Universității din București, 2015.

22. Quirynen M, De Soete M, van Steenberghe D. Infectious risks for oral implants: A review of the literature. Clin Oral Implants Res. 2002;13(1):1-19. 